\title{
Understanding the HIV/STI prevention needs of men who have sex with men in Kenya
}

Washington Onyango-Ouma

Harriet Birungi

Population Council

Scott Geibel

Population Council

Follow this and additional works at: https://knowledgecommons.popcouncil.org/departments_sbsr-hiv

Part of the Family, Life Course, and Society Commons, Gender and Sexuality Commons, and the International Public Health Commons

How does access to this work benefit you? Let us know!

\section{Recommended Citation}

Onyango-Ouma, Washington, Harriet Birungi, and Scott Geibel. 2006. "Understanding the HIV/STI prevention needs of men who have sex with men in Kenya," Horizons Research Summary. Washington, DC: Population Council. 


\section{Hgrizons}

\section{UNDERSTANDING THE HIVISTI Prevention Needs of Men Who Have Sex with Men in Kenya}

Most respondents in a Nairobi study of men who have sex with men are aware of HIVISTIs and are taking measures to reduce their risk. However, condom use is not universal and reported STI symptoms are common. Targeted interventions, such as confidential counseling as part of VCT and STI services, and peer education to foster partner reduction, condom use, and correct use of lubricants are needed.

U nderstanding the sexual behaviors
of populations who are vulnerable
to HIV is an important component in the battle against the AIDS pandemic. Yet policymakers in developing countries, particularly in Africa, have often overlooked men who have sex with men as a vulnerable group because of stigmatization of homosexual behavior and denial of the existence of men who have sex with men and the role they may play in HIV transmission (Parker and Carballo 1990; McKenna 1996). A growing body of literature, however, not only documents the presence of this population in Africa (Murray 1998; Simooya 2001; Niang et al. 2003; Attipoe 2004) but also the importance of reaching them with information and services to prevent HIV and other sexually transmitted infections

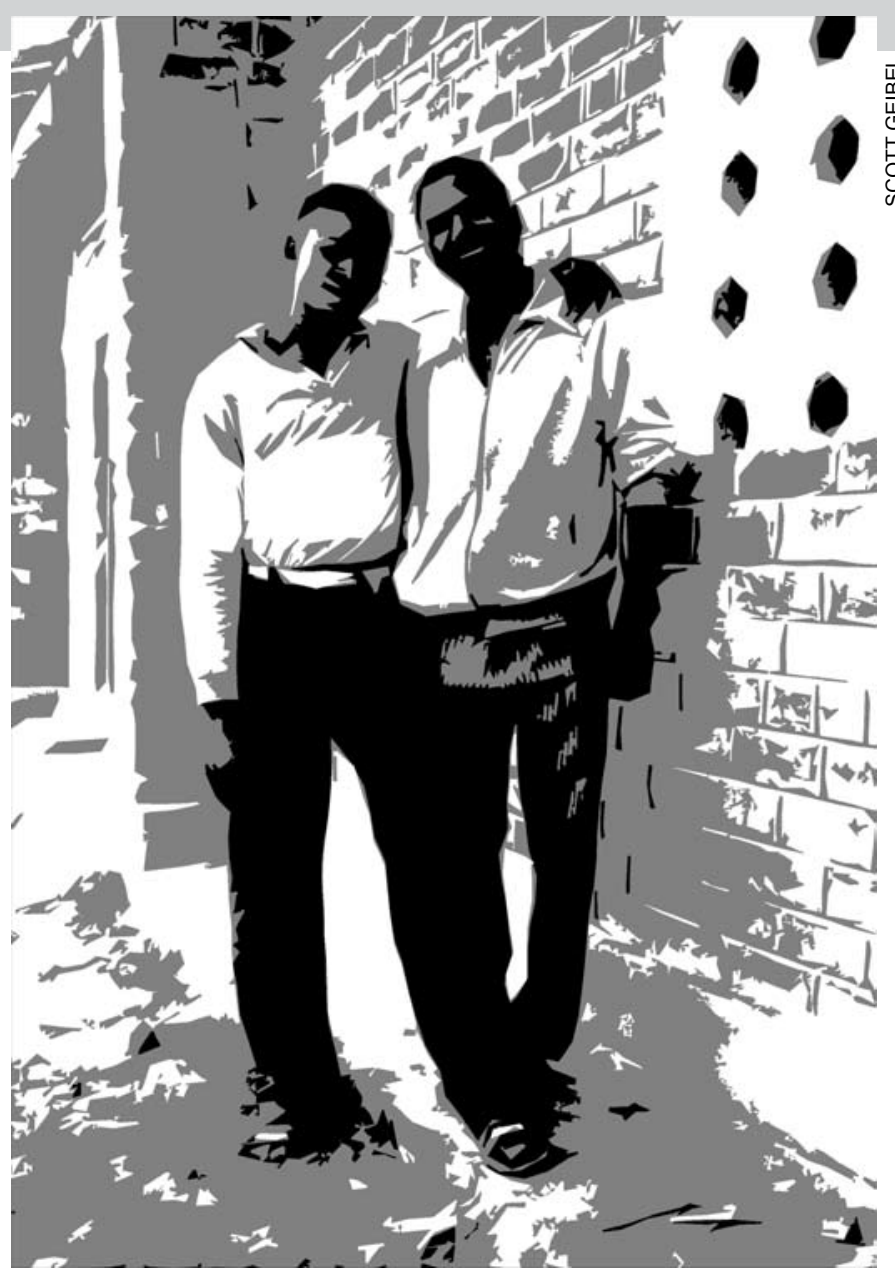

Ignoring men who have sex with men and excluding them from prevention programs has enormous health implications.

(STIs) (UNAIDS 2000; Office of the United States Global AIDS Coordinator 2004).

Despite increasing awareness of the role men who have sex with men can play in the dynamics of HIV transmission in Africa, research on this group in Kenya has been limited. In 
response to this gap, researchers from the Institute of African Studies (IAS) at the University of Nairobi and the Horizons and FRONTIERS Programs of the Population Council undertook a study of men who have sex with men in Nairobi. The overall goals of the study were to understand the extent to which men who have sex with men are at risk of HIV and other STIs, identify the factors associated with risk behaviors, and determine their sexual health needs in order to develop appropriate interventions.

The study proposal received ethical review and clearance from the Population Council Institutional Review Board in New York, the Kenya National Council for Science and Technology, and the Kenyatta National Hospital Ethics and Research Committee in Nairobi. Approval from all review boards was achieved by November 2003, and research activities were conducted between February and August 2004.

In addition to seeking ethical approval, the study established a local advisory committee to advise the research which included representatives of NASCOP, KANCO, educational and advocacy organizations that work with men who have sex with men, and others.

"Some of the populations most affected by HIVI AIDS are the most difficult to reach through conventional health programs... men who bave sex with men... are among those who are most marginalized in society and have the least access to basic health care. Developing and implementing interventions with some of these groups is even more difficult because of stigma and discrimination."

-Office of the United States Global AIDS Coordinator (2004)

\section{Study Methods}

Because of the paucity of information on men who have sex with men in Nairobi, the study was exploratory and descriptive. The study used three methods to collect data: (1) a quantitative survey of 500 Kenyan men, ages 18 and older, who have had sexual intercourse with one or more male partners; (2) in-depth interviews with a sample of these men, plus gatekeepers (i.e., individuals who interact with men who have sex with men either socially or professionally) and service providers; and (3) ethnographic observations in social settings where men who have sex with men congregate. The quantitative survey was implemented first, in early 2004, followed by the in-depth interviews and ethnographic observations; all respondents gave informed consent to participate in the study.

\section{Key Findings}

\section{Men who have sex with men are not a negli- gible population in Nairobi.}

Within a period of two months, the researchers identified 500 Kenyan men, ages 18 to 55, through snowball sampling and interviewed them for the study. Respondents were relatively young (median age 26 years) and from diverse socioeconomic backgrounds, ranging from the unemployed to educated professionals. The survey sample includes those with no occupation (15 percent), students (21 percent), sex workers (14 percent), small-scale earners (16 percent), professional or steady income earners (15 percent), and those with jobs in which they regularly interact with other men who have sex with men (19 percent), as determined by the study's ethnographic observations, such as masseurs, hairdressers, musicians, and taxi drivers. 


\section{The sexual behavior of men who have sex with men has implications for both men's and women's reproductive bealth.}

Over two-thirds of the sample (69 percent) report ever having sex with a woman; seven percent of respondents are currently married and seven percent are divorced/separated/widowed. Twenty-two percent have at least one child. Many respondents remain sexually active with women; 20 percent of those who have ever had sex with a woman $(\mathrm{n}=$ 344) report having vaginal sex in the past month, and 7 percent report having anal sex with a woman in the past month. When asked to describe their sexual identity, nearly a fourth ( 23 percent) say they are bisexual.

\section{Men who have sex with men are vulnerable to stigma, discrimination, and violence.}

Most respondents perceive community stigma and discrimination to be major problems in their lives. When asked which problem they discuss most often with friends, 63 percent mention stigma- related issues. In the past 12 months, a third of respondents report experiencing a stigmatizing/discriminatory incident, such as public humiliation, and 22 percent have experienced verbal, physical, or sexual violence (Table 1). Survey findings show that sex workers are significantly more likely than other respondents to report an incident of stigma/ discrimination (59 percent vs. 29 percent; $\mathrm{p}<0.001)$ and violence (39 percent vs. 19 percent; $\mathrm{p}<0.001)$ in the previous year.

\section{Study respondents report high levels of con- dom use.}

Condoms are widely available throughout Nairobi, and 77 percent of respondents are aware that consistent condom use helps prevent STI/HIV transmission. Seventy-five percent report using a condom at last anal sex with a male partner, and 58 percent say they "always" use condoms. "Never use" of condoms was reported by 11 percent of the sample, and was significantly associated with having only one male partner in the past year $(\mathrm{p}<0.001)$.

Table 1 MSM experiencing stigma, discrimination, and violence in past 12 months $(n=500)$

\begin{tabular}{lc}
\hline & $\%$ \\
\hline Experienced stigma/discrimination (any form) & 33 \\
Aggression and/or humiliation in public & 26 \\
Alienation/harassment by family/friends/neighbors & 8 \\
Discrimination in the workplace & 6 \\
Refusal of service & 3 \\
Eviction/expulsion from place of residence & 1 \\
Other & 2 \\
Experienced violence (any form) & $\mathbf{2 2}$ \\
Verbal & 14 \\
Physical & 12 \\
Sexual & 5 \\
Other & 4 \\
\hline
\end{tabular}

Note: Percentages may not add to 100 percent, as multiple responses were possible. 
Use of oil-based lubricants, which can make condoms vulnerable to breakage, is a major problem.

Lubrication for anal sex is used by 92 percent of respondents. But only 26 percent of the sample who are aware of the use of lubricants during penetrative sex $(n=475)$ correctly know that only a water-based lubricant should be used with latex condoms. The most commonly used lubricant is oil-based Vaseline/petroleum jelly—used by 84 percent of the survey sample. Water-based lubricants such as KY Jelly are used by less than half (41 percent) of respondents.

\section{Sex with multiple partners is common among study respondents.}

During the past week, 18 percent of respondents report having two or more partners. When asked about the past month and the past year, this figure increases to 47 percent and 79 percent, respectively (Figure 1). The median number of partners in the past year is three, which does not reflect 30 percent of the sample that "could not remember the actual number" of partners. However, there is a substantial subgroup of men (21 percent) who report having only one partner in the previous year.
Men who have had only one partner or experienced violence in the past year are significantly less likely to use condoms.

As shown in Table 2, multivariate analysis reveals that having only one partner in the past 12 months is an important predictor of unprotected sex at last receptive anal sex, unprotected sex at last insertive anal sex, and never use of condoms. More than half (51 percent) of those who did not use a condom at last sex $(n=124)$ did so because they trust their partner.

Victims of physical, verbal, or other forms of violence in the past 12 months are also significantly more likely to not use a condom at last receptive anal sex, have unprotected sex at last insertive anal sex, and to "never use" condoms. This may be because men whose lives are characterized by violence are less able to negotiate condom use than other men.

Some factors have a protective effect on condom use. For example, respondents who have ever attended a discussion group or educational session on HIV or STIs are half as likely to not have used condoms during their last act of receptive anal sex. Respondents who know someone with HIV/AIDS are half as likely to have not used a condom during their last act of insertive anal intercourse.

Figure 1 Percent reporting abstinence, monogamy, and multiple partners

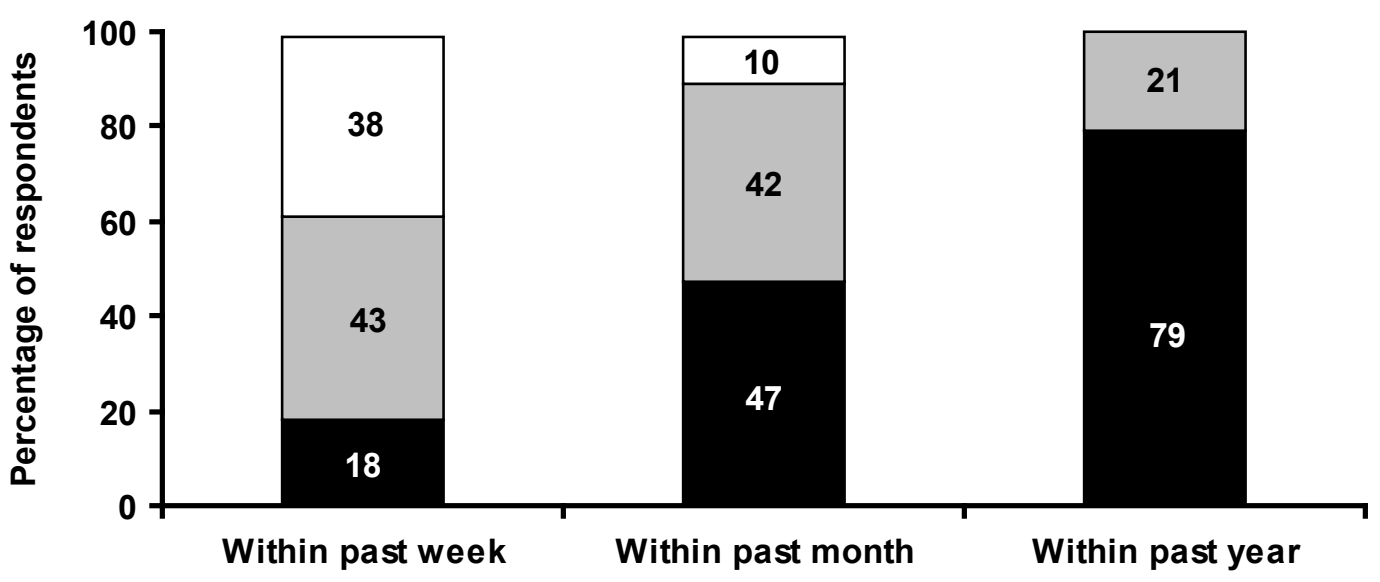
$\square$ No partners
$\square$ One partner only
Two or more partners


Table 2 Multivariate analysis of predictor variables related to unprotected sex with men

\begin{tabular}{|c|c|c|c|c|c|c|}
\hline & \multicolumn{2}{|c|}{$\begin{array}{c}\text { UAR } \\
n=282 \\
r^{2}=0.08\end{array}$} & \multicolumn{2}{|c|}{$\begin{array}{c}\text { UAla }^{\mathrm{a}} \\
\mathrm{n}=427 \\
\mathrm{r}^{2}=0.09\end{array}$} & \multicolumn{2}{|c|}{$\begin{array}{c}\text { "Never-use" of condoms } \\
n=500 \\
r^{2}=0.16\end{array}$} \\
\hline & $\begin{array}{l}\text { Odds } \\
\text { ratio }\end{array}$ & $95 \% \mathrm{Cl}$ & $\begin{array}{l}\text { Odds } \\
\text { ratiob }\end{array}$ & $95 \% \mathrm{Cl}$ & $\begin{array}{l}\text { Odds } \\
\text { ratio }\end{array}$ & $95 \% \mathrm{Cl}$ \\
\hline Has primary or higher education & 0.63 & $(0.29-1.38)$ & 0.45 & $\left(0.20-1.00^{c}\right)^{*}$ & 0.67 & $(0.24-1.88)$ \\
\hline Had only 1 male partner in past 12 months & 2.44 & $(1.32-4.52)^{* *}$ & 2.57 & $(1.48-4.46)^{* *}$ & 3.23 & $(1.68-6.19)^{\star \star *}$ \\
\hline Had 1 or more female sexual partners in past month & 0.57 & $(0.24-1.35)$ & 0.70 & $(0.35-1.41)$ & 0.13 & $(0.02-0.96)^{*}$ \\
\hline $\begin{array}{l}\text { Victim of physical, verbal, or other violence in past } \\
12 \text { months }\end{array}$ & 2.44 & $(1.35-4.39)^{* *}$ & 1.96 & $(1.13-3.37)^{*}$ & 2.45 & $(1.24-4.84)^{*}$ \\
\hline $\begin{array}{l}\text { Ever attended discussion group or session on } \\
\text { HIVISTIs }\end{array}$ & 0.53 & $(0.31-0.89)^{*}$ & 0.61 & $(0.37-0.99)^{\star}$ & 0.56 & $(0.30-1.07)$ \\
\hline Ever had an HIV test & 0.87 & $(0.52-1.47)$ & 0.71 & $(0.44-1.13)$ & 0.70 & $(0.37-1.33)$ \\
\hline Received money for sex in past 12 months & 0.52 & $(0.30-0.92)^{*}$ & 0.58 & $(0.35-0.95)^{\star}$ & 0.26 & $(0.12-0.54)^{\star \star *}$ \\
\hline Knows someone who has/had HIVIAIDS & 0.85 & $(0.37-1.91)$ & 0.43 & $(0.22-0.85)^{*}$ & 1.05 & $(0.41-2.71)$ \\
\hline
\end{tabular}

a $U A R=$ Unprotected anal receptive at last sex; UAI = Unprotected anal insertive at last sex

b Odds ratios are based on multiple logistic regression adjusting for all other factors

c Upper confidence limit includes 1.00 due to rounding up.

${ }^{*} p<0.05,{ }^{* *} p<0.01,{ }^{* * *} p<0.001$

\section{About half of respondents report ever having an STI symptom.}

In the past 12 months, 6 percent of survey respondents report having genital or anal discharge and 5 percent report genital or anal sores. Other symptoms among survey respondents in the past 12 months are genital pain (12 percent), burning urination (14 percent), and genital or anal itching (11 percent). Forty-seven percent report ever having an STI symptom, of which 80 percent $(\mathrm{n}=233)$ sought treatment during the last episode.

\section{The practice of oral sex is associated with reported STI symptoms.}

Multivariate analysis reveals that respondents who practice oral sex are significantly more likely than other men to report at least one STI symptom in the past 12 months. Further analysis shows that genital/anal discharge and genital/anal sores are reported almost exclusively by respondents who practice oral sex compared to those who do not (genital/anal discharge, 9 percent vs. 1 percent, $\mathrm{p}<0.001$; genital/anal sores, 8 percent vs. 0 percent, $\mathrm{p}<0.001)$. The practice of oral sex may be a complex indicator of risky sexual behavior, as well as a potential route of transmission for some STIs.

\section{A majority of men in the study have been tested for HIV.}

More than half of respondents (57 percent) have taken an HIV test. This is more than twice the proportion of males in the general population of Nairobi Province (27 percent) who have been tested for HIV (CBS, MOH, and ORC Macro 2004). Of the men who have taken an HIV test $(\mathrm{n}=286), 98$ percent received their test results, and 70 percent had the test performed within the past 12 months.

Although there is high utilization of testing services among survey respondents, the curriculum used to train voluntary counseling and testing (VCT) counselors in Nairobi does not indicate 
what specialized advice counselors should provide to men who have sex with men, or how they should address partner notification and couples testing for this population.

\section{Confidentiality is the most important factor for study respondents when choosing a treat- ment facility.}

Men who have sex with men desire and seek professional medical care from facilities such as clinics, hospitals, and health centers, which are widely available throughout Nairobi. However, respondents report having difficulty finding providers trained to meet their specific sexual health needs. Respondents prefer to receive STI treatment and/ or HIV counseling in private clinics because they are perceived to provide greater confidentiality, the most important factor they cite when choosing a health facility. Other criteria include affordability and close access to quality care.

\section{Men who have sex with men prefer not to discuss treatment and counseling issues with health providers and vice versa.}

In-depth interviews with providers at facilities frequented by survey respondents indicate that the issue of male-to-male sexual behavior is rarely discussed among providers, or between providers and patients. This is despite the fact that providers see male patients with anal sores or ulcers in the throat, which is suggestive of male-to-male sex. According to survey respondents and providers, men who have sex with men do not approach providers for specific advice, as they fear exposure to the legal system since homosexuality is illegal in Kenya, or that providers will discriminate against them. Also, widespread stigmatization of sex between men prevents providers from discussing special prevention issues, creating a missed opportunity for prevention counseling targeted to men who have sex with men.

\section{Study respondents discuss $H I V$ and other STIs within their social networks.}

Findings from the survey reveal that all respondents are aware of HIV and other STIs and have received information on these topics in the past. When asked where they last obtained any information on HIV/STIs, one in five respondents mention their peers. In qualitative interviews, 44 of 57 men say they discuss HIV transmission with their partners, colleagues, and friends. When asked with whom they would consult if they had an STI symptom, 41 percent of survey respondents prefer to seek advice, a referral, or treatment from a man who also has sex with men.

\section{Conclusions}

The results from this research provide important information on the background characteristics, sexual behavior, health-seeking practices, and experiences of stigma and violence of a sample of men who have sex with men in Nairobi, Kenya. Despite the limitations of the snowball sampling methodology, researchers were able to reach a diverse group of men and elicit qualitative and quantitative data that can be used to inform HIV/STI programming in Kenya. The study also shows that research on men who have sex with men can be done in Kenya despite such obstacles as the widespread stigmatization of homosexual behavior and the fact that it is illegal.

Overall, the survey data indicate that a majority of respondents are aware of HIV/STIs and are taking steps to protect their health. These steps include getting tested for HIV, seeking professional treatment for STI symptoms, and using condoms. However, condom use is not universal, particularly among those who are in long-term sexual relationships with only one partner, or are victims of physical, verbal, and/or sexual violence. Moreover, the prevalence of reported STI symptoms is high, which may facilitate the acquisition and transmission of HIV. 
The ease with which this study recruited 500 men through snowball sampling suggests that the population of Kenyan men living in Nairobi who have sex with men is larger than is commonly believed. This situation, combined with the existence of risk behaviors among the study sample such as unprotected sex and multiple partners, may have implications for the development of localized STI and HIV epidemics. Therefore, clinic- and community-based interventions targeted to this population are urgently needed. These interventions could include specialized counseling and peer education as detailed below.

\section{Specialized counseling as part of VCT and STI services that is confidential and sensitive to the needs of men who have sex with men.}

Although a high percentage of survey respondents have taken an HIV test and know their serostatus, VCT services have not trained counselors to provide care and advice to meet the specific sexual health needs of men who have sex with men. The situation is similar in many STI clinics, where providers rarely discuss treatment and prevention issues relevant to their male clients who have sex with other men. Stigmatizing attitudes of providers and their lack of sensitivity are significant barriers to providing appropriate health services, including information about condoms and correct use of lubricants.

The study found that men who have sex with men desire confidential, affordable, and quality care, and prefer to receive this care from professional health care providers. To improve utilization, services will need to respond to their concerns about stigmatization of male-to-male sexual behavior and their desire for strict confidentiality. Thus, VCT and STI clinic staff need training on the HIV/STI prevention needs of men who have sex with men, counseling strategies for addressing risk behaviors, and the importance of confidential and de-stigmatizing service delivery.

\section{Peer education that addresses the HIVISTI risks of multiple partners, unprotected sex, and incorrect use of lubrication.}

The study found that men who have sex with men-whether as partners or friends - play an important role in passing on information about HIV and other STIs. These discussions revolve around preventive and protective measures that can be adopted by men and that respond to their needs. Study findings also highlight the importance of increasing exposure to discussions about HIV/STIs because respondents who had attended a discussion group or educational session were significantly more likely to use condoms. In addition, a high proportion of survey respondents noted that they would seek advice regarding STI symptoms from other men who have sex with men, which also supports the notion of creating a peer education program for this population.

Peer educators could be trained to encourage the use of water-based lubricants for anal sex, the use of condoms for any penetrative sex act with male or female partners, and a reduction in the number of sexual partners. Peer educators could also help men who have sex with men explore the issues of partner trust and intimacy as barriers to condom use, particularly among those in longer-term relationships with a single partner. These issues are not unique to men who have sex with men, but are also formidable obstacles to condom use within heterosexual relationships.

Peer education may also have an important role to play in helping men who have sex with men who are more marginalized within society-those who have been victims of stigma, discrimination, or violence. The study found that these men are more likely to engage in unprotected sex and report STI symptoms. A peer education program that emphasizes personal empowerment and responsibility and offers social support may help this particularly vulnerable population to adopt HIV/STI protective behaviors. 


\section{Research Utilization}

The final report of the study - the only study conducted in Kenya on the subject matter that used systematic research methods-has been discussed with and disseminated to officials at both the National HIV/AIDS and STD Control Program and National AIDS Control Council, to help inform government programs. The report was also recently distributed and discussed at a roundtable meeting in Kenya, sponsored by the Urgent Action Fund for Women's Human Rights, where NGOs and stakeholders set an agenda for reaching men who have sex with men with programs and services, as well as at a UNAIDS and International HIV/AIDS Alliance roundtable meeting in Geneva.

May 2006

\section{References}

Attipoe, Dela. 2004. "Fighting HIV in Ghana requires addressing homosexuality" Essay based on the study "Revealing the Pandora Box or Playing the Ostrich?: A Situational Appraisal of Men Having Sex with Men in the Accra, Ghana Metropolitan Area and its Environs." The Gully 2004-2005: Online magazine. http://www.thegully.com/ essays/gaymundo/0403_gay-men_hiv_ghana/msm_ghana_intro_ summary.html, accessed August 16, 2005.

Central Bureau of Statistics (CBS) [Kenya], Ministry of Health (MOH) [Kenya], and ORC Macro. 2004. Kenya Demographic and Health Survey 2003. Calverton, Maryland: CBS MOH, and ORC Macro.

McKenna, N. 1996. On the Margins: Men Who Have Sex with Men and HIV in the Developing World. London: PANOS Institute.

Murray, S.O. 1998. "Homosexuality in 'traditional' sub-Saharan Africa and contemporary South Africa." An overview, in S. O. Murray and W. Roscoe (eds.). Boy-wives and Female Husbands. Studies on African Homosexualities. New York: St. Martin's Press, pp $1-18$.
Niang, C. et al. 2003. "'It's raining stones': stigma, violence and HIV vulnerability among men who have sex with men in Dakar, Senegal," Culture, Health and Sexuality 5(6): 499-512.

Office of the United States Global AIDS Coordinator. 2004. "The President's emergency plan for AIDS relief: U.S. five-year global HIV/AIDS strategy." Washington DC: Office of the United States Global AIDS Coordinator.

Parker, R.G. and M. Carballo. 1990. "Qualitative research on homosexual and bisexual behavior relevant to HIV/AIDS," The Journal of Sex Research 27(4): 497-525.

Simooya, O.O. 2001. "Behind walls': a study of HIV risk behaviours and seroprevalence in prisons in Zambia," AIDS 15(13): 1741-1744.

UNAIDS. 2000. Report on Global HIVIAIDS epidemic. Geneva: UNAIDS.

\section{Acknowledgments}

The researchers would like to acknowledge Sam Kalibala, Chris Castle, Professor Isaac Nyamongo, and individuals from the following organizations: USAID/Kenya, Kenya National AIDS Control Program (NASCOP), Kenya National Council for Science and Technology (NCST), and Liverpool VCT Centre, as well as Emmanuel Kamau, Jeremy Mirie, Alex Rutto, Moses Orege, Eric Murage, Dr. Julius Rogena, Otiende Amollo, staff of the International Centre for Reproductive Health (ICRH) in Mombasa, Placide Tapsoba, Amadou Moreau, Susan Cherop-Kaai, and Norah Omenda.

Above all, we would like to thank the individuals who agreed to participate in this research.

Study investigators include W. Onyango-Ouma Institute of African Studies/University of Nairobi, Harriet Birungi of FRONTIERS/ Population Council, and Scott Geibel of Horizons/Population Council.

Suggested citation: Onyango-Ouma, W., Harriet Birungi, and Scott Geibel. 2006. "Understanding the HIV/STI prevention needs of men who have sex with men in Kenya," Horizons Research Summary. Washington, D.C.: Population Council.

\section{Hqrizons}

Population Council/Horizons

Communications Unit

4301 Connecticut Avenue, NW

Suite 280

Washington, DC 20008

Population Council

Tel: 202-237-9400

Fax: 202-237-8410

horizons@pcdc.org

www.popcouncil.org/horizons

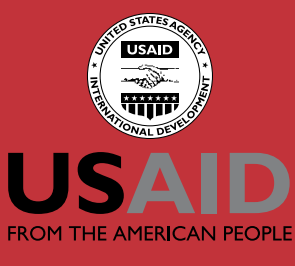

This publication was made possible through support provided by the President's Emergency Plan for AIDS Relief through the Office of HIV/ AIDS, Bureau of Global Health, U.S. Agency for International Development (USAID), under the terms of Award No. HRN-A-00-97-00012-00. The opinions expressed herein are those of the authors and do not necessarily reflect the views of USAID. 